\title{
Prevalence of Microalbuminury and Associated Risk Factors in a Population of Diabetics Followed at the Marc Sankale Center of Dakar
}

\author{
Sow Djiby*, Diédhiou Demba, Ndour Michel Assane, Diallo Ibrahima Mané, Diouf Mahecor, \\ Ka-Cissé Marie, Sarr Anna, Ndour Mbaye Maimouna \\ Clinique Médicale II, Centre Hospitalier Abass Ndao, UCAD, Dakar, Senegal \\ Email: ^drdjiby@yahoo.fr
}

How to cite this paper: Djiby, S., Demba, D., Assane, N.M., Mané, D.I., Mahecor, D., Marie, K.-C., Anna, S. and Maimouna, N.M. (2018) Prevalence of Microalbuminury and Associated Risk Factors in a Population of Diabetics Followed at the Marc Sankale Center of Dakar. Open Journal of Internal Medicine, 8, 24-32.

https://doi.org/10.4236/ojim.2018.81004

Received: October 30, 2017

Accepted: January 21, 2018

Published: January 24, 2018

Copyright $\odot 2018$ by authors and Scientific Research Publishing Inc. This work is licensed under the Creative Commons Attribution International License (CC BY 4.0).

http://creativecommons.org/licenses/by/4.0/ (c) (i) Open Access

\begin{abstract}
Introduction: To describe the epidemiologic profile, clinical and paraclinical of diabetics presenting microalbuminuria at Marc Sankale center. Patients and methods: We have done cross-sectional and retrospective study in a descriptive and analytic view or way. It happened within 6 months. Diabetic patients who performed the nycthemeral urinary albumin dose and mentioned in the file were included. The last study is considered as a positive one from 30 to $299 \mathrm{mg} / 24 \mathrm{~h}$ : Microalbuminuria. The creatinine has been noted and the clearing of the creatinine is calculated through the formula of Cockcroft and Gault. The statistical analysis of data has been done thanks to software such as excel 2013 and SPSS VER 18.0. Results: 221 patients have been noted with $70 \%$ women and $30 \%$ men. The age varied between 30 years and 85 years with an average of 56, 62 against 9.97 years. Sixty three (63) patients have microalbuminuria (29\%); creatinine has been regularized to 25 patients with $14.8 \%$ of cases. Among the microalbuminuria patients having completed the creatinine, 32 patients (42.7\%) and $16(21.3 \%)$ are respectively in a state of chronical renal failure, light and moderated. Conclusion: The microalbuminuria is frequent to diabetics. But in our series a starting renal insufficiency could precede that microalbuminuria.
\end{abstract}

\section{Keywords}

Diabetics, Microalbuminuria, Renal Insufficiency, Senegal

\section{Introduction}

Diabetes doesn't stop increasing in Africa like everywhere in the world due to the settlement and the aging of the population [1]. It's right that the prevalence 
is caused principally by the diabetes of type 2. Except acute complications (hyperglycemia, infections) that diabetics confronted, the diabetes bad control exposes in a long run several chronical complications. Among them: Nephropathy Diabetics (ND) represents one of the most serious; more through the taken supported than the morbidity and the cardiovascular mortality that are related to it [2] [3]. However the ND can be prevented and treated when it is diagnosed in a subclinical state. The stage corresponds to microalbuminuria which when the taken supported is late can progress toward the microalbuminuria and renal failure [4] [5].

The few studies of prevalence on microalbuminuria and the macro albuminuria that had been done in Sub Saharan Africa were consecrated to diabetes of type 2 [6] [7].

The present work aims at studying the epidemiological and clinical profile of a population of diabetics followed at Marc sankale center in Dakar and presenting a microalbuminuria.

\section{Patients and Methods}

The study was carried out at the Medical Clinic II of the Abass Ndao Hospital Center in Dakar. This medical clinic II is the national reference center in the management of metabolic endocrine diseases in Senegal since 1960. This is a descriptive cross-sectional study of renal function in a diabetic population. The recruitment of our patients was done over a period of three months. The study population consisted of known diabetic patients, regardless of type and source, followed centrally during the study period. Included in our work, all patients with diabetes and microalbuminuria. Were excluded all diabetic patients who had both a microalbuminuria and a urinary tract infection.

A card was established to serve as a data collection base. This card is approved by the Hospital Ethics Committee. It included: marital status, lifestyle, family and personal history of the patient, anthropometric data, clinical manifestations, and diabetes study. The data was collected from patient records and is listed in the form. The variables in the study were:

Socio professional data: age, sex, occupation, address, provenance. The study of diabetic sugar is interested in a types of diabetes. Hypertension: this is a blood pressure $\geq 140$ and/or $90 \mathrm{mmHg}$, or that the patient is known hypertensive treated. Obesity is defined by the body mass index BMI and is calculated according to height and weight according to the formula: BMI = Weight (in $\mathrm{kg}) /\left[\right.$ Height $\left(\right.$ in $\left.\left.\mathrm{m}^{2}\right)\right]$.

We also used the International Obesity Task Force classification to rank patients by body mass index . Normal values are 18.5 to $24.9 \mathrm{~kg} / \mathrm{m}^{2}$. Overweight is reported when $24.9<\mathrm{BMI}<30 \mathrm{~kg} / \mathrm{m}^{2}$ and obesity when $\mathrm{BMI}>29.9 \mathrm{~kg} / \mathrm{m}^{2}$ [8].

The Para clinical report: we collected the fasting blood glucose HbA1c, lipid balance, serum creatinine, creatinine clearance, urea, serum uremia. The quality of control of diabetes was considered good when HbA1c was less than 7\%, ac- 
ceptable when HbA1c ranged between $7 \%$ and $8 \%$ and poor if the result was greater than $8 \%$ [8].

Lipid status: dyslipidemia is defined by the presence of one or more of the following abnormalities and/or a known history of dyslipidemia according to the National Cholesterol Education Program Adult Treatment Panel III (NCEPATPIII): Total cholesterol $>2 \mathrm{~g} / \mathrm{l}$. Triglycerides $>1.5 \mathrm{~g} / \mathrm{l}$. HDL-cholesterol $<$ $0.5 \mathrm{~g} / \mathrm{l}$ in women and $<0.4 \mathrm{~g} / \mathrm{l}$ in men, LDL-cholesterol $>1.6 \mathrm{~g} / \mathrm{l}$. Creatinine and creatinine clearance its normal value is between 80 and 130 moll/1. To estimate DFG, we use the most classic Cockcroft and Gault formula [9]:

Renal function is considered normal if clearance exceeds $90 \mathrm{ml} / \mathrm{min}$. There is mild renal impairment between 60 and $89 \mathrm{ml} / \mathrm{min}$. renal impairment is moderate for a clearance of 30 to $59 \mathrm{ml} / \mathrm{min}$. It is severe between 15 to $29 \mathrm{ml} / \mathrm{min}$ and lethal below $15 \mathrm{ml} / \mathrm{min}$. The urea normal blood urea values are between $0.15 \mathrm{~g} / \mathrm{l}$ and $0.45 \mathrm{~g} / \mathrm{l}$. Serum uric acid values are between 25 and $70 \mathrm{mg} / \mathrm{l}$. Normal albuminuria, microalbuminuria and macro albuminuria were defined, respectively, by urinary creatinine albumin below $30 \mathrm{mg} / \mathrm{g}$, between 30 and $299 \mathrm{mg} / \mathrm{l}$ and greater than or equal to $300 \mathrm{mg} / 1$ [9].

The data has been entered into the Microsoft Office Excel software 2013 and SPSS VER 18.0.

\section{Results}

In the study period 766 diabetes patients were received and 221 among them have done a microalbuminuria. A positive microalbuminuria is a prevalence of $27.14 \%$ and 3 microalbuminuria (1.35\%). The average age is 56,5 years with extremes ranging from 22 to 81 years. The age group between 40 to 59 years is more represented with $31.49 \%$ more than 60 years old people represented $23.55 \%$. 44 women $(70 \%$, ) with a sex ratio of 0.43 . Our population consist of $49 \%$ housekeepers, traders $22 \%$, civil servants $7 \%$, retreated people $3 \%$, and workers $3 \%$.

\section{Study of Diabetes Mellitus}

About $87 \%$ of our patients are type 2 diabetics. The duration of diabetes was less than 5 years in 66 patients (25\%). Diabetes evaluating for more than 10 years is $46 \%$. Hyperglycemia (more than 1.26 ) is noted in $79.66 \%$ of patients. The average was 2.19 with a maximum of $5.22 \mathrm{~g} / \mathrm{l}$. Glycated hemoglobin is less than $7 \%$ in $15 \%$ of patients and more than $7 \%$ in $80.85 \%$. The average is $10.96 .43 \%$ of our population are hypertensive. Among those who are in a state of obesity 10 are noted with a moderated obesity and 4 with obesity $43 \%$. LDL-cholesterol: The average is 1.25 with a maximum of $2.65 \mathrm{~g} / \mathrm{l}$. the LDL cholesterol level is more than $1 \mathrm{~g} / \mathrm{l}$ in $53.9 \%$ of cases. HDL-cholesterol: the average is $0.56 \%$ and $12.6 \%$ have a low rate, less than $0.4 \mathrm{~g} / \mathrm{l}$. Total Cholesterol: The average is 2.11 with a maximum of $3.79 \mathrm{~g} / \mathrm{l} .52 .3 \%$ have a total cholesterol level more than $2 \mathrm{~g} / \mathrm{l}$. Triglycerides: the average is 0.98 . About $12.6 \%$ have a triglyceride level more than 1.5 
g/l. Table 1 shows the comparison between pathological microalbuminuria and normal microalbuminuria Creatinine: $25.49 \%$ have a serum creatinine above the norm. A hyper uremia is noted in $6.3 \%$ of the population. The clearance of creatinine: $28.20 \%$ have mild renal insufficiency. Renal failure is moderate in $17.94 \%$ of cases and is severe in $15.38 \%$. We also have $5.12 \%$ with fatal renal failure (Table 2).

\section{Discussion}

Our study has some limitations. The collected data was exhaustive clinically and para clinically. Proteinuria, biopsy posture, renal echography, renal biopsy went

Table 1. Comparison between pathological microalbuminuria and normal microalbuminuria.

\begin{tabular}{|c|c|c|}
\hline Patients characteristics & $\begin{array}{c}\text { Normal } \\
\text { Microalbuminuria }\end{array}$ & $\begin{array}{c}\text { Positive } \\
\text { Microalbuminuria }\end{array}$ \\
\hline Men & 33.5 & 30 \\
\hline Women & 66.5 & 70 \\
\hline Middle age & 56.6 & 56.5 \\
\hline type 2 diabetes & 89.2 & 87 \\
\hline $\mathrm{DD}<5$ ans & 27 & 25 \\
\hline $5<\mathrm{DD}<10$ & 24 & 8 \\
\hline $\mathrm{DD}>10$ ans & 28 & 46 \\
\hline Overweight & 27.8 & 15.8 \\
\hline Obesity & 10.6 & 22.1 \\
\hline HTA & 36.7 & 43 \\
\hline Average glycemia & 1.79 & 2.19 \\
\hline hyperglycemia & 63.2 & 75 \\
\hline Average $\mathrm{HbAlc}$ & 8.15 & 10.96 \\
\hline $\mathrm{HbAlc}>7 \%$ & 51.8 & 60 \\
\hline LDL & 1.3 & 1.25 \\
\hline $\mathrm{LDL}>1 \mathrm{~g} / \mathrm{l}$ & 64.5 & 53.9 \\
\hline Average HDL & 0.54 & 0.56 \\
\hline $\mathrm{HDL}<0.4 \mathrm{~g} / 1$ & 15.8 & 12.6 \\
\hline Average $\mathrm{CHT}$ & 2.04 & 2.11 \\
\hline $\mathrm{CHT}>2 \mathrm{~g} / \mathrm{l}$ & 46.8 & 52.3 \\
\hline Averge TG & 0.9 & 0.98 \\
\hline $\mathrm{TG}>1.5 \mathrm{~g} / \mathrm{l}$ & 26.5 & 12.6 \\
\hline Average Creatinie & 9.89 & 14.3 \\
\hline Creatinine $>13 \mathrm{mg} / \mathrm{l}$ & 5 & 20 \\
\hline Average Urea & 1.55 & 3.3 \\
\hline Urea $>0.45 \mathrm{~g} / 1$ & 6.9 & 12 \\
\hline uricemia $>70 \mathrm{mg} / \mathrm{l}$ & 6.3 & 6.3 \\
\hline
\end{tabular}


Table 2. Distribution of patients according to renal function based on creatinine clearance.

\begin{tabular}{cc}
\hline Renal clearance & Percentage \\
\hline sup 90 & $33.3 \%$ \\
{$[60 ; 89]$} & $28.20 \%$ \\
{$[30 ; 59]$} & $17.94 \%$ \\
{$[15 ; 29]$} & $15.38 \%$ \\
inf 15 & $5.12 \%$ \\
\hline
\end{tabular}

to the quest of diabetic nephropathy. One of the objective of that study was to determine the prevalence of microalbuminuria in a diabetic population. The collective data indicates a prevalence of $29 \%$. Studies on diabetic nephropathy in Africa reported various rate of prevalence. Some indicated lower rates than our: $11.6 \%$ in Sudan and $17.1 \%$ in Uganda [10] [11]. Ciss and al found in a study in Dakar in 2002 a frequency of $16.2 \%$ and $22.6 \%$ according to the technic of dosage used [12]. Other African authors found some results comparable to ours. It is the case of Lokrou [13] and Coulibaly [14] who found respectively $26 \%$ and $27 \%, 39 \%$. The ND prevalence in the type 1 diabetes is approximately $20 \%$ to $30 \%$ in historical series [15]. Published for almost 15 years ago. Rissassi [16] found in their study in Kinshasha a frequency of microalbuminuria of 39 (21.9\%) versus $13(7.3 \%)$ for the macroalbuminuria and 126 (70.8\%) for the norm albuminuria. The prevalence of the ND in type 2 diabetic patients coming from the whole population is amazingly variable ranging from $2 \%$ to $46 \%$. Yameogo in a Senegal study of type 2 diabetic population found a prevalence of 36 , $6 \%$ [17]. That disparity of prevalence can be explained through racial ethnic diference or the technic of urine collective. The macroalbuminuria prevalence (1.39\%) is inferior to that found by Elyoussef [18] in Maroccco (5\%) in 2011. Similarly Moumbe Tamba and al [19] in Douala (Cameroon 2013) and Agboton and al in Benin [20] find respectively a prevalence of $25 \%$ and $8.3 \%$.

There was a great feminine predominance in our study (70\%). In Coulibaly' study we found the same. The average age of our specimen is 56.5 years [14]. This average is closed to that of Taleb (2008) [21] in Lebanon (54.4 \# 11 years) as well as that of Yameogo and $\mathrm{Al}$ in 2012 [17]: 58.2 \# 9.2 years. In our study the microalbuminuria is present in the early diabetic years in a frequency of $2508 \%$ that is the double after 10 years of the disease evolution (46\%).

The study group of type 2 diabetic patients followed in a prospective way establishes an incidence mixed with the ND order of $6 \%$ to $12 \%$ in 10 years and 2 to $41 \%$ in 20 years after diabetes diagnosis. [22]. The current study shows that the microalbuminuria in now premature and frequent to Senegalese diabetics regardless the period of diabetes evolution. The microalbuminuria yearly incidence increases progressively and reach the woodpecker about 16th year of disease evolution [23]. HTA is found in $43 \%$ of our study population. The prevalence of that association is closed to that found by BenHamouda, Chihoui and $\mathrm{Al}$ 
(2011) [24]: $80 \%$ by Boutar and al [25] = 79.3\% by Eli youssouf: 79.3\% [26].

At revenge the numbers appose to that found by Gatouagui (Bujumbara) [27]: $20.41 \%$ as well as to that of Dembele (Malia): $16.69 \%$ [28]. The combination of arterial hypertension (hypertension) and nephropathy is common. Numerous studies show that high blood pressure is one of the complications of diabetes due to vascular disease. Hypertension is known to be a risk factor for the development and worsening of diabetic nephropathy even at an earlier stage [27]. Most studies have confirmed that optimal control of blood pressure prevents or slows the development of kidney damage during diabetes and reduces morbidity and mortality [29].

The high prevalence of this association (Diabetes-HTA) is a traditional fact, but could be explained in our study, by the aging of our population, dominated to nearly $78.00 \%$ by patients having an age beyond 50 years.

For some authors that dyslipidemia would be explained by microalbuminuria. According to Wang and al [30] the hyperlipidemia causes a risk to develop the nephropathy in type 2 diabetes. In our study a hyperglycemia is noted $78 \%$ of patients. The average $\mathrm{HbA1C}$ is $10.96 \%$. Two random studies done by DCCT and UKPDS [31] have clearly showed the relation that exist between. The increase of HbAa1C (average glycemia) and the exponential increase of complication risk precisely the diabetic nephropathy. The control of $\mathrm{HbAlc}$ is therefore closely linked to the prevention of micro and macrovascular complications related to diabetes.

The light renal failure is $28.2 \%$. Renal insufficiency is moderated in $17.94 \%$ of cases and is severe in $15.38 \%$. In France in 2001, Pouteil-Noble noticed $20 \%$ of IRCT cases [32].

Ce The elevated rate could be explained by bad glycemic balance and the presence of risk like HTA. Diabetes association and the HTA provoke the precocious IRC. The susceptibility of type 2 diabetics to have a vascular disease and almost atherosclerosis lesion favored by the dyslipidemia and arterial hypertension could be explained by the decrease of glomerular filtration rate. In fact the proximal atherosclerosis or distal develop before the state of nephropathy. The detected microalbuminuria is considered as a vascular risk and an endothelial decrease; but not the starting of final glomerulus nephropathy. The rein in that circumstances is victim and not guilty of HTA [33].

In our study dyslipidemia is noted in $52.3 \%$ of patients In T2DM, the correlation of dyslipidemia with ND is described by some authors [34] [35], with an emphasys on cardiovascular risk. Our results also show that the prevalence of obesity differs significantly between the two groups: $10.6 \%$ versus $22.1 \%$. In the literature, several studies have shown a negative effect of obesity or overweight on ND, with an increased risk of renal impairment [34] [35] [36] [37].

The lack of equipment to detect microalbuminuria, but also the uncommon demand for protein band proteinuria and quantitative proteinuria in Senegalese medium explain this result. A sensitization and training policy for curing should be implemented to improve the management of diabetic nephropathy in Seneg- 
al. The management strategy for microalbuminuria in diabetics should be considered on a case-by-case basis. In general, it is primarily aimed at controlling diabetes, moderating protein intake and stopping smoking. The blocking treatment of the renin-angiotensin-aldosterone system is recommended if micro-albuminuria and associated hypertension persist [37].

\section{Conclusion}

Microalbuminuria and even macro albuminuria are very common in diabetics, Senegalese. Improving diabetes control and treating microalbuminuria are essential to prevent kidney failure in diabetics.

\section{References}

[1] King, H., Aubert, R.E. and Herman, W.H. (1998) Global Burden of Diabetes, 1995-2025: Prevalence, Numerical Estimates and Projections. Diabetes Care, 21, 1414-1431. https://doi.org/10.2337/diacare.21.9.1414

[2] Jensen, T., Borch-Johnsen, K., Kofoed-Enevoldsen, A. and Deckert, T. (1987) Coronary Heart Disease in Young Type 1 (Insulin-Dependent) Diabetic Patients with and Without Nephropathy: Incidence and Risk Factors. Diabetologia, 30, 77-81. https://doi.org/10.1007/BF00274218

[3] Borch-Johnsen, K., Andersen, P.K. and Deckert, T. (1985) The Effect of Proteinuria on Relative Mortality in Type 1 (Insulin-Dependent) Diabetes Mellitus. Diabetologia, 28, 590-596. https://doi.org/10.1007/BF00281993

[4] Noubiap, J.J.N., Naidoo, J. and Kengne, A.P. (2015) Diabetic Nephropathy in Africa: A Systematic Review. World Journal of Diabetes, 6, 759-773.

[5] Krzesinski, J.M., Sumaili, K. and Cohen, E. (2007) How to Tackle the Avalanche of Chronic Kidney Disease in Sub-Saharan Africa: The Situation in the Democratic Republic of Congo as an Example. Nephrology Dialysis Transplantation, 22, 332-335. https://doi.org/10.1093/ndt/gfl494

[6] Erasmus, R.T., Oyeyinka, G. and Arije, A. (1992) Microalbuminuria in NoninsulinDependent (type 2) Nigerian Diabetics: Relation to Glycaemic Control, Blood Pressure and Retinopathy. Postgraduate Medical Journal, 68, 638-642. https://doi.org/10.1136/pgmj.68.802.638

[7] Lutale, J.J., Thordarson, H., Abbas, Z.G. and Vetvik, K. (2007) Microalbuminuria among Type 1 and Type 2 Diabetic Patients of African Origin in Dar es Salam, Tanzania. BMC Nephrology, 8, 2. https://doi.org/10.1186/1471-2369-8-2

[8] American Diabetes Association. (2003) Report of the Expert Committee on Diagnosis and Classification of Diabetes Mellitus. Standards of Medical Care in Diabetes. Diabetes Care, 26, 5-20. https://doi.org/10.2337/diacare.26.2007.S5

[9] Cockcroft, D.W. and Gault, M.H. (1976) Prediction of Creatinine Clearance from Serum Creatinine. Nephron, 16, 31-41. https://doi.org/10.1159/000180580

[10] El Mahdi, E.M., Abdel Rahman, I. and Mukhtar, S. (1989) Pattern of Diabetes Mellitus in the Sudan. Tropical and Geographical Medicine, 41, 353-357.

[11] Nambuya, A.P., Otim, M.A., Whitehead, H., Mulvany, D., Kennedy, R. and Hadden, D.R. (1996) The Presentation of Newly-Diagnosed Diabetic Patients in Uganda. QJM, 89, 705-711. https://doi.org/10.1093/qjmed/89.9.705

[12] Cisse, P., Lopez Sall, P., Diop, P.A., Niang, M.S., KaCisse, M.S., Gueye, P.M., et al. 
(2002) Frequency of Microalbuminuria during Diabetes in Dakar (Senegal). Dakar Medical, 42, 151-153.

[13] Lokrou, A., Hortense, M. and Kambou, F.D. Nephropathy Patent of the African Diabetic in RCI Cross-Sectional Study of a Population of 446 Patients in 1994, 35-6 November-December, 546-550.

[14] Coulibaly, H. (1999) Interest of the Determination of Micro-Albuminuria in the Early Diagnosis of Diabetic Nephropathy. Thesis of Medicine, Bamako, No. 35.

[15] Coutant, R. and Limal, M. (2001) Complications of Type 1 Diabetes in Children: State of Affairs. Pediatric Archives, 8, 337-339.

[16] Rissassi, J.R., et al. (2010) Prevalence and Determinants of Microalbuminuria and Macroalbuminuria in Children and Young Adults with Type 1 Diabetes in Kinshasa. Nephrologie \& Therapeutique, 6, 40-46. https://doi.org/10.1016/j.nephro.2009.08.001

[17] Yameogo, N. (2012) Study of Microalbuminuria in a Senegalese Type 2 Diabetic Population. Black African Medicine, 59, 303-308.

[18] Elyoussfi, S. (2011) Diabetic Nephropathy during the First Consultation in Nephrology (About 104 Cases). Thesis Med, FMP, Fez, 118 p.

[19] Tamba Mmbe, S., Ewane, M., Bonny, A., Nikidiaka Muisi, C., Nana, E., Ellong, A., et al. (2013) Micro and Macrovascular Complications of Diabetes Mellitus in Cameroon: Risk Factors and Effects of Diabetic Check-Ups-A Monocentric Observational Study. The Pan African Medical Journal, 15, 141.

[20] Agboton, B. Micro Albuminuria in Type 2 Diabetics South of Benin: Frequency of Chronic Renal Failure Previous. Journal of the Society of Clinical Biology of Benin, 23.

[21] Taleb, N., Salti, H., Al Mokaddam, M., Merheb, M., Salti, I. and Nasrallah, M. (2008) Prevalence and Determinants of Albuminuria in a Cohort of Diabetes Patients in Lebanon. Annals of Saudi Medicine, 28, 420-425.

https://doi.org/10.5144/0256-4947.2008.420

[22] Weekers, L. and Krzesinski, J.-M. (2005) Diabetic Nephropathy. Revue Medicale De Liege, 60, 479-486.

[23] Andersen, A.R., Sandahhl Christiansen, J.K., Anderson, J.K., Kreiner, S. and Deckert, T. (1983) Diabetic Nephropathy in Type 1 (Insulin-Dependent) Diabetes: An Epidemiological Study. Diabetologia, 25, 496-501.

https://doi.org/10.1007/BF00284458

[24] Ben-Hamouda-Chihaoui, M. (2011) Evaluation of Blood Pressure Balance by Ambulatory Measurement of Blood Pressure and Study of Factors Associated with Poor Blood Pressure Control in 300 Diabetic Type 2 Hypertensive Treated. Annales de Cardiologie et D'Angeiologie, 60, 71-76.

[25] Bouattar, T., Ahid, S., Benasila, S., et al. (2008) Progression Factors of Diabetic Nephropathy: Care and Evolution. Nephrology \& Therapy, 5, 181-187.

https://doi.org/10.1016/j.nephro.2008.12.004

[26] Afifa, K. and Asma, S.B. (2016) Harzallah Nabil and al: Dépistage de la néphropathie dans le diabète sucré: le test micral est-il valide chez tous les diabétiques? International Journal of Chronic Diseases, 2016, 7 p. https://doi.org/10.1155/2016/2910627

[27] Gaturagi, C., Nsabiyumva, F., Bizimana, P., Ahounou, F., Dansou, H. and Amoussou-Guenou, D. (2013) Epidemiological Study of Diabetes in Urban Bujumbura: Case of 2000 Subjects of the Buyenzi Urban District. Black African Medicine, 60, 
91-95.

[28] Dembele, M., Sidibé, A., Traore, H., Chombou Hic-Zounet, B., Traore, A., Diallo, D., et al. (2000) Association HTA-Diabetes Mellitus in the Department of Internal Medicine of the G-Bamako Point Hospital. Black African Medicine, 47, 276-280.

[29] Adler, Al., Stevens, R.J., Mawley, S.E., et al. (2003) Development and Progression of Nephropathy in Type 2 Diabetes: The United Kingdom Prospective Diabetes Study UKPDS. Kidney International, 63, 225.

[30] Wang, S., Wang, L., Zhou, Y., et al. (2012) Prevalence and Control of Dyslipidemia among Diabetic Patients with Micro Albuminuria in a Chinese Hospital. Diabetes and Vascular Disease Research, 10, 169-178.

https://doi.org/10.1177/1479164112454756

[31] UK Prospective Diabetes Study (UKPDS) Group (1998) Intensive Blood-Glucose Control with Sulphonylureas or Insulin in the Treatment of Patients with Type 2 Diabetes (UKPDS 33). The Lancet, 352, 837-853. https://doi.org/10.1016/S0140-6736(98)07019-6

[32] Pouteil-Noble, C., Villar, E., et al. (2001) Epidemiology and Etiology of Chronic Renal Failure. La Revue Du Praticien, 51, 365-371.

[33] Chadban, S., Howell, M., Twigg, S., Thomas, M., Jerums, G., Campbell, D., et al. (2010) Prevention and Management of Chronic Kidney Disease in Type 2 Diabetes. Nephrology, 15, S162-S194.

[34] Bouzid, C., Smida, H., Kacem, A., et al. (2011) Renal Insufficiency in Type 2 Diabetics. Frequency and Associated Factors. Medical Tunisia, 89, 10-15.

[35] Agarwal, N., Sengar, N.S., Jain, P.K. and Khare, R. (2011) Nephropathy in Newly Diagnosed Type 2 Diabetics with Special Stress on the Role of Hypertension. Journal of the Association of Physicians of India, 59, 145-147.

[36] Zelmanovitz, T., Gerchman, F., Balthazar, A.P., et al. (2009) Diabetic Nephropathy. Diabetology \& Metabolic Syndrome, 1, 10. https://doi.org/10.1186/1758-5996-1-10

[37] Garcia, C., Mayaudon, H., Bordier, L., Leberre, J.P., Dupuy, O. and Bauduceau, B. (2007) Responsibility for Nocturnal Blood Pressure in the Development of Diabetic Nephropathy in Patients with Diabetics. Arch Heart and Vessels, 8, 668-672. 